\title{
Percutaneous Local Injection of Ethanol and Mitoxantrone in Treatment of Hepatocellular Carcinoma
}

\author{
Ahmed S Bihery', Mostafa H El-Shamy ${ }^{1}$, Talaat E El-Mokadem², \\ Tarik I Zaher ${ }^{1}$, Walid A Abd EI Dayem ${ }^{1}$, Talaat Fathy ${ }^{1}$, \\ Mohamad Emara ${ }^{1}$ \\ ${ }^{1}$ Tropical Medicine Department, Faculty of Medicine,Zagazig University, Egypt. \\ ${ }^{2}$ Clinical Oncology Department, Faculty of Medicine,Zagazig University, Egypt.
}

Corresponding author: Ahmed Salah Bihery email: ahmedbihery@ yahoo.com mobile:

$+2(010) 0089628$ $+2(055) 2380474$

Received :15/9/2011

Accepted after revision: 9/10/2011

Keywords : Hepatocellular carcinoma; Ethanol; Mitoxantrone; Ablation
Background and study aim: New therapeutic choices have been developed for hepatocellular carcinoma (HCC), including percutaneous ablation therapy, transarterial chemoembolization, radiation therapy and molecular target therapy. Ablation of liver tumors is currently the main alternative to formal liver resection. This work aimed at comparing percutaneous ethanol injection (PEI) with combined percutaneous ethanol and mitoxantrone injection (PIM) in treatment of HCC.

Patients and methods: This study included 125 patients with $131 \mathrm{HCC}$ lesions which were randomly divided into two groups; group I composed of 68 lesions in 65 patients treated with PEI. Group II composed of 63 lesions in 60 patients treated with PEI and PIM. Clinical assessment, laboratory evaluation

\section{INTRODUCTION}

Hepatocellular carcinoma (HCC) is a highly malignant cancer and it is the sixth most common cancer worldwide and the third most common cause of cancer related deaths with higher prevalence in Asia and sub-Saharan Africa [1].

Advancement in diagnostic radiology and nuclear medicine contributed to the accurate and early diagnosis of HCC. Ultasound, CT, Triphasic CT and MRI are used in diagnosis of these tumors [2].

Surgical resection, liver transplantation and cryosurgery are considered the best curative options for HCC. Regional interventional therapies have led to a major and CT studies were performed to all patients pre treatment and at 3,6 , and 12 months post treatment. Each focal lesion was considered as one subject.

Results: The percentage of ablation in both groups at 3, 6, 12 months were $60.3 \%, 48.5 \%$ and $39.7 \%$ in group I respectively versus $85.5 \%, 74.6 \%$ and $68 \%$ in group II respectively with a statistical significant difference between the two groups. There is an increased number of local recurrence in group I compared to group II. Side effects and complications are comparable in both groups.

Conclusion: Combination of PEI and PIM is better than PEI alone without additional complication and recurrence rate seemed to be better in combination therapy than PEI alone.

breakthrough in the management of unresectable HCC[3].

Furthermore, experiences in interventional radiology, radiation oncology and surgery fields have grown, and new therapeutic choices have been developed including percutaneous ablation therapy, transarterial chemoembolization (TACE), radiation therapy and molecular target therapy[4]. Ablation of liver tumors is currently the main alternative to formal liver resection [5]. Percutaneous ethanol injection (PEI) is a procedure of easy execution, good tolerability and low cost, which can be applied in repeated sessions [2]. 
Mitoxantrone is a cycle specific anthracyclin which induces persistent intracellular DNA damage. It is used as an anticancer agent and has demonstrated clinical activity when administered via multiple routes: intravenous, intraperitoneal, intrapleural, intrapericardial, or intrathecal [6]. Mitoxantrone was selected for palliative local treatment of malignant liver lesions because of its low tissue toxicity, high intratumoral concentration after intratumoral instillation, since it has a tendency to remain at the application site [7].

This work aimed at comparing PEI with combined PEI and intralesional mitoxantrone(PIM) in treatment of HCC.

\section{PATIENTS AND METHODS}

This prospective interventional study was conducted in Tropical medicine and Clinical Oncology Departments, Faculty of Medicine, Zagazig university, Egypt, during the period from February 2009 to May 2011 and included 125 patients presented with 131 focal hepatocellular carcinoma lesions, the lesions were randomly divided into 2 groups;

Group I: Comprised 68 focal lesions presented in 65 patients ,which were injected intralesionally with ethanol in multiple sessions.

Group II: Comprised 63 focal lesions presented in 60 patients, which were injected intralesionally with ethanol in multiple sessions followed by intralesional injection with Mitoxantrone.

Each focal lesion was considered as one subject.

The diagnosis of HCC was based on typical characters of focal lesion in triphasic CT: filling of the dye in arterial phase and rapid fade out in venous and delayed phases, CT andor ultrasound focal lesions with a serum alpha-fetoprotein $>200$ $\mathrm{IU} / \mathrm{ml}$ or by histological confirmation.

Inclusion criteria in both groups are :

1- Single lesion 2-5 $\mathrm{cm}$ or 2 lesions each $<3 \mathrm{~cm}$ [8],

2- Child- Pugh class A and B ,

3- Serum creatinine $<2 \mathrm{mg} / \mathrm{dl}$,

3- Performance status 0-2 [9] and

4- Absence or controllable ascites .

\section{Pretreatment assessment}

Pre-treatment assessment of all patients was done by full history taking, thorough clinical examination, laboratory investigations including $\mathrm{CBC}$, liver function, kidney function, $\alpha$ fetoprotein, serological examination for $\mathrm{HCV}$ and HBV. Radiological examination including $\mathrm{X}$ ray chest, CT study, ultrasound and ultrasound guided biopsy when indicated.

\section{Ethanol injection.}

All lesions were injected by absolute alcohol; ultrasound guided in multiple sessions, twice weekly, under complete aseptic condition and 10 $\mathrm{mg}$ midazolam as a sedative agent.

The same operator used spinal needle (20 gauge) to inject ethanol intralesionally and leave the needle for 2 minutes in place, then injection of local anesthetic during withdrawal of the needle to minimize the irritant effect of refluxed ethanol to the capsule.

The total amount of ethanol can be calculated according to the following equation:

$$
\mathrm{V}=4 / 3 \pi(\mathrm{r}+0.5)^{3}
$$

Where: $V=$ Volume of ethanol, $\pi=22 / 7, r=$ radius of the tumor by $\mathrm{cm}$ plus $0.5 \mathrm{~cm}$ as safety margin [10].

The average amount per session was $6.8 \mathrm{cc}$, with average 5 sessions per lesion and average amount of $35 \mathrm{cc}$ per lesion which was calculated according to the above mentioned equation used by Shiina et al [10].

\section{Mitoxantrone injection.}

This was done to patients of group II after complete sessions of ethanol.

Ultrasound guided injection of mitoxantrone mixed with lipidol at the time of injection in a single session, the dose of mitoxantrone is 0.5 $\mathrm{mg}$ per cubic centimeter of the tumor size.

Re-evaluation of the patients was done by laboratory investigations, ultrasound and triphasic CT after treatment and every 3 moths up to one year.

\section{Statistical analysis}

Data were checked, entered and analyzed using SPSS 15 for Windows. Data were expressed as mean \pm SD for quantitative variable, number and percentage for qualitative one. Chi-squared $\left(X^{2}\right)$ or fisher exact, $\mathrm{t}$ test and paired $\mathrm{t}$ test were used 
when appropriate. $\mathrm{P}<0.05$ was considered significant.

\section{RESULTS}

Clinical presentations of the studied patients is shown in table 1 . Group I included 48 male patients and 17 females with a mean age of 61.1 years. Group II included 44 male patients and 16 females with a mean age of 60 years. There was no statistically significant difference as regard age and sex between the studied groups .

Chronic HCV infection was the predominant virus in our study, 112 patients were $\mathrm{HCV}$ antibodies positive, where 11 patients were HBsAg positive and two patients had coinfection of both viruses. Local ablation therapy for HCC is associated with a variety of complications as shown in table (2). The most frequent complication was tolerable pain while intolerable pain (needs analgesics) detected in $27.6 \%$ and $20 \%$ of patients in group I and group II respectively. The most serious complications were less frequent and tend to occur in subjects in group I who developed peritoneal collection, subcapsular hematoma and pleural effusion each one detected in 2 subjects $(3.1 \%)$, while portal vein thrombosis detected in 3 subjects $(4.6 \%)$. All these complications were controlled by conservative management .Table (3) compares biochemical parameters among patients of groups I before and 3 months after injection, there was no statistically significant difference as regard all parameters except for serum alphafeto protein( $\alpha$ FP) and AST which showed statistically significant improvement after treatment. Table (4) compares biochemical parameters among patients of groups II before and 3 months after injection, there was no statistically significant difference as regard to $\alpha \mathrm{FP}$, AST, serum bilirubin( BIL), serum albumin ( ALB) and serum creatinin (CRT), where ALT and prothrombin time (PT) show statistically significant improvement in these patients after injection. Table 5 and 6 compare the success of ablation and rate of recurrence at 3,6 and 12 months with good ablation recorded in group II than in group I.

Table (1): Clinical presentations of all patients

\begin{tabular}{|l|c|c|c|c|}
\hline & $\begin{array}{c}\text { GroupI } \\
\text { (n=65 patients) }\end{array}$ & $\%$ & $\begin{array}{c}\text { GroupII } \\
\text { (n=60 patients) }\end{array}$ & $\%$ \\
\hline Right hypochondrial pain & 35 & $53.8 \%$ & 34 & $56.7 \%$ \\
\hline Anorexia & 22 & $33.8 \%$ & 15 & $25 \%$ \\
\hline Loss of weight & 14 & $21.5 \%$ & 16 & $26.7 \%$ \\
\hline Low grade fever & 11 & $16.9 \%$ & 9 & $15 \%$ \\
\hline Splenomegally & 38 & $58.5 \%$ & 35 & $58.3 \%$ \\
\hline Lower limb edema & 23 & $35.4 \%$ & 19 & $31.7 \%$ \\
\hline History of jaundice & 6 & $9.2 \%$ & 5 & $8.3 \%$ \\
\hline History of ascites & 4 & $6.2 \%$ & 5 & $8.3 \%$ \\
\hline
\end{tabular}

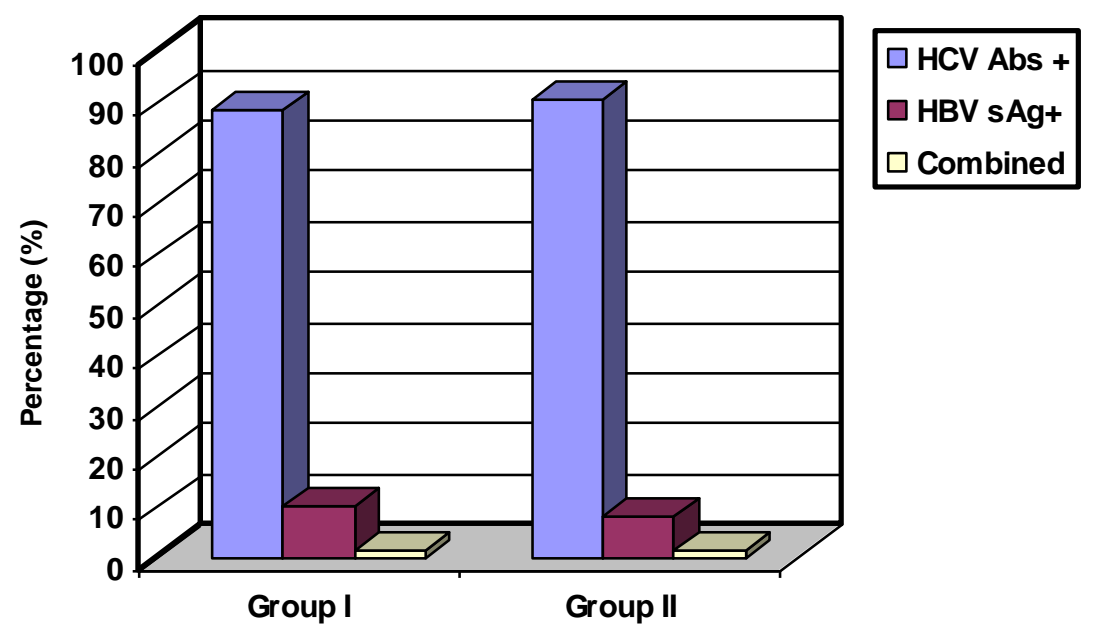

Fig. (1): Viral serology among the studied groups

Bihery et al. Afro-Egypt J Infect Endem Dis 2011; 1 (2):28-36

www.mis.zu.edu.eg/ajied/home.aspx 
Table (2): Frequency of complications after injection in group I and group II

\begin{tabular}{|c|c|c|c|c|}
\hline \multirow[t]{2}{*}{ Complication } & \multicolumn{2}{|c|}{$\begin{array}{c}\text { Group I } \\
(\mathrm{n}=65 \text { patients })\end{array}$} & \multicolumn{2}{|c|}{$\begin{array}{c}\text { Group II } \\
(\mathrm{n}=60 \text { patients })\end{array}$} \\
\hline & No & $\%$ & No & $\%$ \\
\hline Pain & & & & \\
\hline tolerable & 47 & $72.3 .1 \%$ & 44 & $73.3 \%$ \\
\hline Intolerable & 18 & $27.6 \%$ & 12 & $20 \%$ \\
\hline Fever & 8 & $12.3 \%$ & 5 & $8.3 \%$ \\
\hline Vomiting & 7 & $10.8 \%$ & 9 & $15 \%$ \\
\hline Peritoneal collection & 2 & $3.1 \%$ & 1 & $1.7 \%$ \\
\hline Pleural effusion & 2 & $3.1 \%$ & - & \\
\hline Subcapsular hematoma & 2 & $3.1 \%$ & 1 & $1.7 \%$ \\
\hline Portal vein thrombosis & 3 & $4.6 \%$ & 1 & $1.7 \%$ \\
\hline
\end{tabular}

Table (3): Biochemical tests in group I before and 3 months after injection.

\begin{tabular}{|c|c|c|c|c|}
\hline & Group I before & Group I after & $\mathrm{t}$ & $\mathrm{P}$ \\
\hline \multirow{2}{*}{$\begin{array}{l}\alpha \text { FP } \\
(\text { normal } 10 \mathrm{u} / \mathrm{dl} \text { ) }\end{array}$} & $247.9 \pm 477$ & $227.2 \pm 421$ & \multirow{2}{*}{2.38} & \multirow[b]{2}{*}{0.019} \\
\hline & $1.8-2690$ & $2-1950$ & & \\
\hline \multirow{2}{*}{$\begin{array}{l}\text { AST } \\
\text { (normal up to } 40 \mathrm{u} / \mathrm{dl} \text { ) }\end{array}$} & $69.6 \pm 32.3$ & $61.7 \pm 19.3$ & \multirow{2}{*}{2.19} & \multirow{2}{*}{0.03} \\
\hline & $19-150$ & $29-117$ & & \\
\hline \multirow{2}{*}{$\begin{array}{l}\text { ALT } \\
\text { (normal up to } 40 \mathrm{u} / \mathrm{dl} \text { ) }\end{array}$} & $51.3 \pm 20.7$ & $46.9 \pm 11$ & \multirow{2}{*}{1.7} & \multirow{2}{*}{0.07} \\
\hline & 16-115 & $27-80$ & & \\
\hline \multirow{2}{*}{$\begin{array}{l}\text { BIL } \\
\text { (normal } 0.3-1.2 \mathrm{mg} / \mathrm{dl} \text { ) }\end{array}$} & $1.22 \pm 0.4$ & $1.32 \pm 0.47$ & \multirow{2}{*}{0.4} & \multirow{2}{*}{0.67} \\
\hline & $0.6-2.1$ & $0.8-3.1$ & & \\
\hline \multirow{2}{*}{$\begin{array}{l}\text { ALB } \\
\text { (normal 3.5-5.3 g/dl) }\end{array}$} & $3.5 \pm 0.4$ & $3.4 \pm 0.47$ & \multirow{2}{*}{1.31} & \multirow{2}{*}{0.19} \\
\hline & $2.9-4.5$ & $2.5-4.4$ & & \\
\hline \multirow{2}{*}{$\begin{array}{l}\text { ALP } \\
\text { (normal 75-250 u/dl) }\end{array}$} & $238+40$ & $245+45$ & \multirow{2}{*}{1.6} & \multirow{2}{*}{0.12} \\
\hline & $115-350$ & $76-590$ & & \\
\hline \multirow{2}{*}{$\begin{array}{l}\text { PT } \\
\text { (normal 11-14 second) }\end{array}$} & $14.4 \pm 0.9$ & $14.6 \pm 1.3$ & \multirow{2}{*}{0.6} & \multirow{2}{*}{0.75} \\
\hline & $12.2-16$ & $12.05-18.0$ & & \\
\hline \multirow{2}{*}{$\begin{array}{l}\text { CRT } \\
\text { (normal 0.5-1.4 mg/dl) }\end{array}$} & $0.98 \pm 0.16$ & $0.99 \pm 0.2$ & \multirow{2}{*}{1.0} & \multirow{2}{*}{0.3} \\
\hline & $0.6-1.3$ & $0.6-1.6$ & & \\
\hline
\end{tabular}

Table (4): Biochemical tests in group II before and 3 months after injection .

\begin{tabular}{|c|c|c|c|c|}
\hline & Group II before & Group II after & $\mathrm{t}$ & $\mathrm{P}$ \\
\hline \multirow{2}{*}{$\begin{array}{l}\alpha \text { FP } \\
(\text { normal } 10 \mathrm{u} / \mathrm{dl})\end{array}$} & $330.6 \pm 580.4$ & $185.5 \pm 320.4$ & \multirow{2}{*}{1.009} & \multirow{2}{*}{0.31} \\
\hline & $4.8-1890$ & $3-1250$ & & \\
\hline \multirow{2}{*}{$\begin{array}{l}\text { AST } \\
\text { (normal up to } 40 \mathrm{u} / \mathrm{dl} \text { ) }\end{array}$} & $72.5 \pm 37.2$ & $66.8 \pm 48.3$ & \multirow{2}{*}{0.752} & \multirow{2}{*}{0.45} \\
\hline & $13-143$ & $32-270$ & & \\
\hline \multirow{2}{*}{$\begin{array}{l}\text { ALT } \\
\text { (normal up to } 40 \mathrm{u} / \mathrm{dl} \text { ) }\end{array}$} & $53.7 \pm 29.1$ & $46.8 \pm 15.2$ & \multirow{2}{*}{2.52} & \multirow{2}{*}{0.014} \\
\hline & $11-147$ & $15-76$ & & \\
\hline \multirow{2}{*}{$\begin{array}{l}\text { BIL } \\
\text { (normal 0.3-1.2 mg/dl) }\end{array}$} & $1.13 \pm 0.32$ & $1.4 \pm 1.26$ & \multirow[b]{2}{*}{1.67} & \multirow{2}{*}{5.1} \\
\hline & $0.6-1.8$ & $0.8-6.9$ & & \\
\hline \multirow{2}{*}{$\begin{array}{l}\text { ALB } \\
(\text { normal 3.5-5.3 g/dl) }\end{array}$} & $3.4 \pm 0.46$ & $3.27 \pm 0.41$ & \multirow{2}{*}{1.69} & \multirow{2}{*}{0.09} \\
\hline & $2.8-4.3$ & $2.5-4.5$ & & \\
\hline \multirow{2}{*}{$\begin{array}{l}\text { ALP } \\
\text { (normal 75-250 u/dl) }\end{array}$} & $225 \pm 41$ & $255 \pm 41$ & \multirow{2}{*}{1.4} & \multirow{2}{*}{0.21} \\
\hline & $107-355$ & $71-650$ & & \\
\hline \multirow{2}{*}{$\begin{array}{l}\text { PT } \\
\text { (normal 11-14 second) }\end{array}$} & $14.1 \pm 1.3$ & $13.8 \pm 0.9$ & \multirow{2}{*}{2.95} & \multirow{2}{*}{0.004} \\
\hline & $11.7-16.3$ & $12.5-16.5$ & & \\
\hline \multirow{2}{*}{$\begin{array}{l}\text { CRT } \\
\text { (normal 0.5-1.4 mg/dl) }\end{array}$} & $1.01 \pm 0.2$ & $1.03 \pm 0.2$ & \multirow{2}{*}{1.76} & \multirow{2}{*}{0.08} \\
\hline & $0.6-1.5$ & $0.8-1.4$ & & \\
\hline
\end{tabular}


Table (5): Follow up of complete ablation in both groups at 3,6 and 12 months after injection.

\begin{tabular}{|c|c|c|c|c|c|c|}
\hline \multirow{2}{*}{} & \multicolumn{2}{|c|}{$\begin{array}{c}\text { Group I } \\
\text { (n=68 lesions) }\end{array}$} & \multicolumn{2}{c|}{$\begin{array}{c}\text { Group II } \\
\text { (n=63 lesions) }\end{array}$} & \multirow{2}{*}{ X2 } & \multirow{2}{*}{ P } \\
\cline { 2 - 5 } & No & $\%$ & No & $\%$ & & \\
\hline 3 months & 41 & 60.3 & 54 & 85.7 & 10.6 & 0.0011 \\
\hline 6 months & 33 & 48.5 & 47 & 74.6 & 9.3 & 0.002 \\
\hline One year & 27 & 39.7 & 43 & 68 & 10.01 & 0.001 \\
\hline
\end{tabular}

Table (6): Follow up of complete ablation in both groups at 6 and 12 months after injection.

\begin{tabular}{|l|c|c|c|c|c|c|}
\hline \multirow{2}{*}{} & \multicolumn{2}{|c|}{$\begin{array}{c}\text { Group I } \\
\text { (n=41 lesions) }\end{array}$} & \multicolumn{2}{c|}{$\begin{array}{c}\text { Group II } \\
\text { (n=54 lesions) }\end{array}$} & \multirow{2}{*}{ X2 } & P \\
\cline { 2 - 5 } & No & $\%$ & No & $\%$ & & \\
\hline After 6 months & & & & & & \\
Still ablated & 33 & $80.4 \%$ & 47 & $87 \%$ & 0.75 & 0.38 \\
New lesions & 4 & $9.7 \%$ & 4 & $7.4 \%$ & 1.29 & 0.25 \\
Local Recurrence & 4 & $9.7 \%$ & 3 & $5.5 \%$ & 0.03 & 0.87 \\
Died & 3 & $7.3 \%$ & 1 & $1.8 \%$ & 0.64 & 0.9 \\
\hline After one year & 27 & $65.8 \%$ & 43 & $79.6 \%$ & 2.28 & 0.13 \\
Still ablated & 6 & $14.6 \%$ & 7 & $13 \%$ & 1.29 & 0.25 \\
New lesions & 8 & $19.5 \%$ & 4 & $7.4 \%$ & 0.03 & 0.87 \\
Local Recurrence & 8 & $19.5 \%$ & 7 & $13 \%$ & 0.64 & 0.9 \\
Died & 33 & $80.5 \%$ & 48 & $87 \%$ & 0.75 & 0.38 \\
One year survival & & & & & & \\
\hline
\end{tabular}
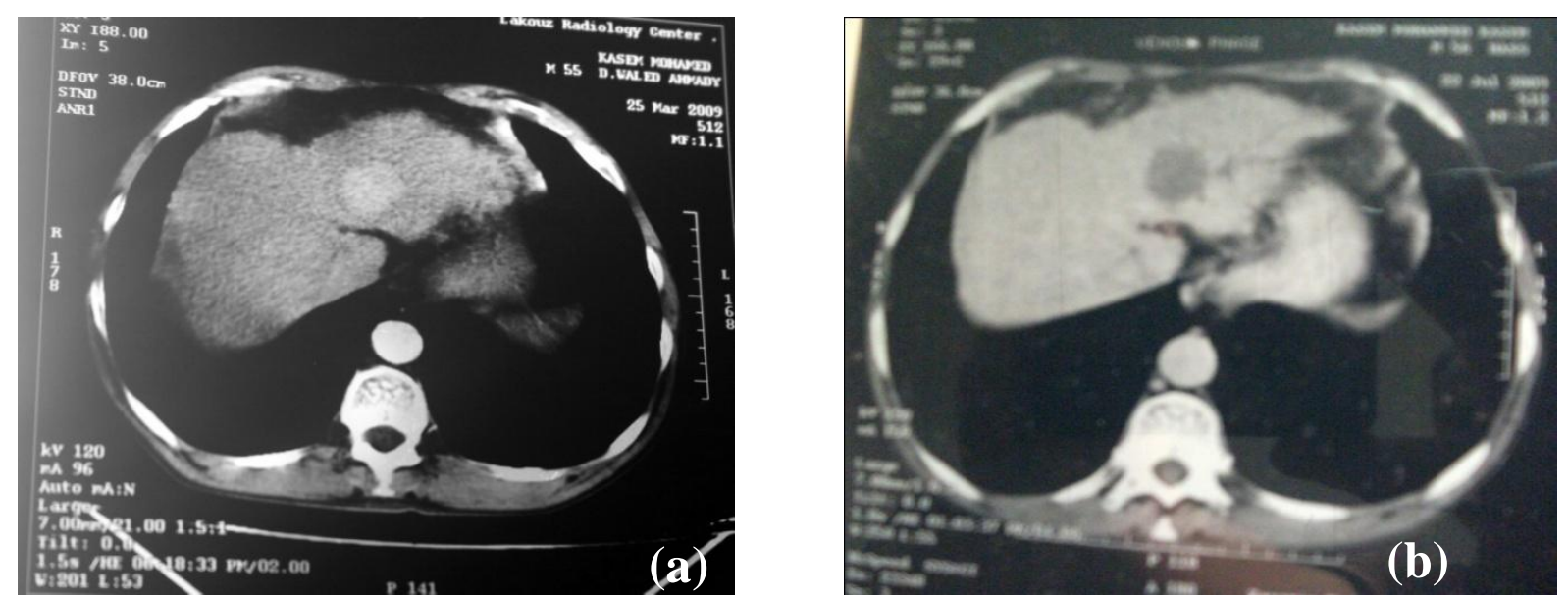

Fig. (2): (a) CT study shows HCC with rapid uptake in the arterial phase before treatment. (b) CT study of the same focal lesion shows no uptake (complete ablation) after ethanol injection. 

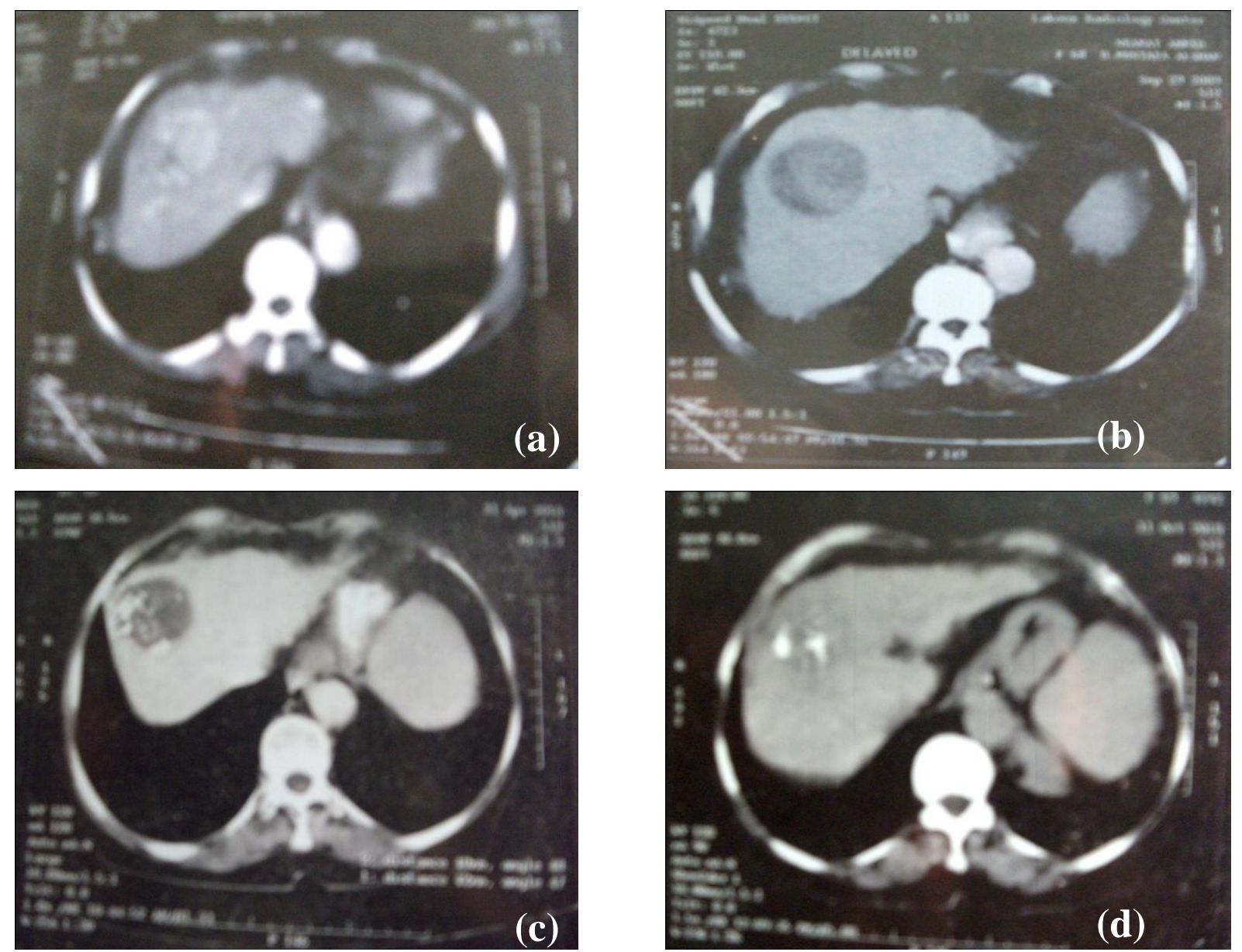

Fig. (3): (a, b) CT study showing HCC before treatment. (c) CT study showing complete ablation 3 months after combined ethanol and mitoxantrone (no uptake in the arterial phase) with lipidol inside. (d) CT study showing complete ablation 6 months after combined ethanol and mitoxantrone (no uptake in the arterial phase) with lipidol inside.

\section{DISCUSSION}

Percutaneous ablation is the best treatment option for patients with early stage HCC who are not suitable for surgical resection or transplantation [8]. Ethanol induces immediate coagulative necrosis and injury then thrombosis of tumor cells and enable the complete ablation of small neoplastic lesions without adversely affecting liver function.PEI is a procedure of easy execution, good tolerability and low cost, which can be applied in repeated sessions [2] and that is why we used this maneuver for percutanous ablation in our low resource community. PEI performed under ultrasonographic guidance achieves complete tumor necrosis in $70 \%-80 \%$ of solitary $\mathrm{HCC} \leq$ $3 \mathrm{~cm}$ [11] and in almost $100 \%$ in tumors less than $2 \mathrm{~cm}$. Tumor necrosis is less likely to be achieved in large tumors; $70 \%$ necrosis is reported for tumors between 2 and $3 \mathrm{~cm}$ and $50 \%$ necrosis for HCC between 3 and $5 \mathrm{~cm} \mathrm{[12].}$
The median age of patients in this study is 60.7 years which is slightly higher than ages recorded in another Egyptian study and estimated to be 56 years [13], and this may be due to improvement of general health by preventive programs and introduction of antiviral agents in treatment of chronic HCV and HBV.

In our study the male $(n=92)$ to female $(n=33)$ ratio was 2.7:1, which is in agreement with both the local Egyptian ratio 3:1 stated by Gad ElMawla et al.[13], and the international ratios of 2.6:1 in China and 3.1:1 in Italy [14].

HCC usually develops following chronic liver inflammation caused by hepatitis $\mathrm{C}$ or $\mathrm{B}$ virus [15]. This is also applied to our study where chronic HCV infection is the most common cause of liver disease in our series $(89.6 \%$ of patients versus $8.8 \%$ chronic $\mathrm{HBV}$ and $1.6 \%$ cases of coinfection) and this reflects the situation in Egypt where $\mathrm{HCV}$ prevalence 
reported among several population groups reachs up to $20 \%$ [16], while low prevalence of chronic HBV coincide with intermediate endemicity (2-8\%) of HBsAg carrier rate in Egypt[17]. These results are not in agreement with Abdel-Wahab et al., [18] who found positive virology in only $82.5 \%$ of HCC patients (61\% HCV, $14.5 \% \mathrm{HBV}$ and $7 \%$ coinfection), this may be attributed to the advancement in the diagnostic methods .

Abdominal pain (right upper quadrant), anorexia and loss of weight were the most common presenting symptoms, while liver cirrhosis and splenomegaly were the predominant signs, this is in agreement with Kew [19].

As regard treatments for HCC, liver transplantation can eliminate tumors and cirrhosis at the same time, and is considered to be the most appropriate treatment for patients with early HCC [20]. But, the lack of liver donors is a major limitation [21]. In Egypt further obstacles include high prevalence of chronic liver diseases in particular $\mathrm{HCV}$ in addition to financial constraints for the high cost of transplantation and the lack of experience for living donor liver transplantation.

Till the time this study is planned for in February 2009, many studies had been published to evaluate effect of percutanous injection of ethanol in treatment of HCC,but few studies evaluating percutanous injection of mitoxantrone in treatment of $\mathrm{HCC}$ were published and none -to our knowledge- evaluated effect of percutanous combined injection of ethanol and mitoxantrone in treatment of HCC.

In a study done by Sung et al;[22] between January 1995 and April 1999, 64 patients with HCC were treated by PEI as first-line treatment and therapeutic efficacy was assessed by US ,CT and AFP. Overall survival rates at one year was $92 \%$ and the corresponding cancer free survival rates were $56 \%$. The local tumor progression rates were $23 \%$ ( 9 of 39 HCCs ) for tumors $\leq$ $2 \mathrm{~cm}$ in diameter. The local tumor recurrence is comparable to our results(19.5\%), while the survival rate is better in their study due to different etiology of their patients as HCC develop in chronic hepatitis B viral infection with good synthetic function of the liver.

In our study the percentage of complete ablation in group I at 3, 6,12 months after the use of PEI alone is $60 \%, 48.5 \%$ and $39.7 \%$ respectively. Which is in agreement with Sung and his colleagues[22] who obtain the same percentage of ablation in large lesions $2-5 \mathrm{~cm}$ in diameter.

The use of combined PEI and PIM resulted in a significantly higher rates of complete ablation at 3,6 and 12 months: $85.7 \%, 74.6 \%$ and $68 \%$, respectively and indicate the efficacy of mitoxantrone addition to PEI. These results may attributed to effect of ethanol on blood vessels draining the tumor leading to their thrombosis that impair systemic absorption of mitoxantrone and maximize its local effect.

Lipidol has high affinity to malignant hepatocytes, when mixed with mitoxantrone leads to selective uptake by malignant hepatocytes leading to additional ablative effect and more prevention of local recurrence rate observed in group II compared to group I.

The percentage of ablation after treatment with combination of PEI and PIM is $85.7 \%$ after 3 months, These results are comparable with many studies reporting similar frequency of ablation after radiofrequency ablation (RF) in patients with similar criteria[23]. We are in need for further controlled studies to compare RF and combination of PEI and PIM.

Intratumoral instillation of mitoxantrone results in a 1000-fold higher concentration in the tumor compared with intravenous administration. We preferred to do percutaneous interventions to obtain a higher drug concentration within the tumor without systemic toxicity and to preserve the integrity of the healthy liver parenchyma, which is an advantage over (TACE) or repeated surgery. This factor is of paramount importance as survival is dependent on the integrity of the liver function [24].

Farres et al. [25] evaluated PIM in hepatic focal lesions. They used $10 \mathrm{mg}$ of mitoxantrone for lesions $<3 \mathrm{~cm}$ and $20 \mathrm{mg}$ for lesions $>3 \mathrm{~cm}$. Three treatment sessions were performed 1 month apart for each of the 11 lesions. Follow-up by $\mathrm{CT}$ examination one month after therapy showed very low attenuation of the lesion indicating tumor necrosis. All injections were painless except four and patients never required analgesics during or after the procedure. Doses of 10-20 mg PIM produces no side effects and no hematologic toxicity was observed [25]. When we compare these results with our results, there were higher rate of intolerable pain, fever and vomiting and other local aggressive complications, ethanol injection would be accused as the cause of these complications. 
The histologic effects of locoregional mitoxantrone treatment are characterized by complete tumor necrosis in which dead tumor cells are surrounded by an inflammatory infiltrate and a fibrotic organization of liver tissue around the tumor[26] .This structure tends to isolate the lesion, preventing their expansion and promoting the persistence of the drug at the injected site. This fibrous rim reaction could also explain why lesion remain stable and do not shrink after PIM treatment. Furthermore this rim could prevent proliferation of residual cancer cells[25] and this explain absence of aggressive local complications in group II of our study e.g. peritoneal reaction.

The drawback of PIM as with all localized treatments is that it does not preclude the emergence of other tumor foci or the progression of untreated tumors [25].

In this study the rate of local recurrence is higher in group I in comparison to group II and this additional benefit may be attributed to PIM and its induced perilesional fibrous reaction.

In this study the synthetic liver functions and consequently Child class seems to be improved in group II than group I and hence combined use of PEI and PIM seems to be superior to PEI alone.

In conclusion, PEI followed by PIM seems to be better than PEI alone and this is reflected by higher rates of complete ablation of focal hepatic lesions at 3,6 and 12 months. Improvement of synthetic liver functions and consequently Child classes is better in group II than group I.

Funding: Non.

\section{Conflicts of interest: Non.}

Ethical approval: The protocol of the study was approved by the ethical committee of Faculty of Medicine, Zagazig University. Informed consents were obtained from all patients.

\section{REFERENCES}

1. Parkin DM, Bray F, Ferlay J, Pisani P. Global Cancer Statistics, 2002. Cancer J Clin 2005, 55:74-108.

2. Franca AV, Elias Junior J , Lima BL, Martinelli AL,Carrilho FG. Diagnosis, staging and treatment of hepatocellular carcinoma. Braz J Med Biol Res 2004; 37(11): 1689 - 705.

3. Qian J , Feng GS, Vogl T. Combined interventional therapies of hepatocellular carcinoma. World J. Gastroenterol 2003; 9(9): $1885-91$.
4. Kim JK, Han KH, Lee JT ,Paik YH ,Ahn SH ,Lee JD, et al. Long-term clinical outcome of phase IIb clinical trial of percutaneous injection with Holmium-166-Chitosan complex (Milican ${ }^{\circledR}$ ) for the treatment of small hepatocellular carcinoma. Clin Cancer Res 2006; 12: 543 - 8.

5. Wright AS, Mahvi, DM, Haemmerich DG, Lee FT. Minimally invasive approaches in management of hepatic tumors. Surg. Technol. Int 2003; 11: 144 - 53.

6. Zamboglou N, Wurm R, Pape H. Simultaneous radiotherapy and intratumoral instillation of mitoxantrone in locoregional recurrence of head and neck carcinoma. Reg Cancer Treat 1991; 4: $79-84$.

7. Fox ME, Smith PJ. Subcellular localisation of the antitumour drug mitoxantrone and the induction of DNA damage in resistant and sensitive human colon carcinoma cells. Cancer Chemother Pharmacol 1995; 35: 403 - 10.

8. Bruix J, Sherman M. AASLD practice guidlines: Management of Hepatocellular Carcinoma. Hepatology 2005; 42: 5.

9. Oken MM, Creech RH, Tormey DC, Horton J, Davis TE, McFadden ET ,et al. Toxicity And ResponseCriteria Of The Eastern Cooperative Oncology Group. Am J Clin Oncol 1982; 5: 649655.

10. Shiina S, Tagawa K, Unuma $T$, Fugino H, Uta y, Niwa Y,et al. Percutaneous ethanol injection therapy of HCC: analysis of 77 patients. AJR 1990; 155: 1221.

11. Choi D, Kim SH, Lim JH,Cho JM ,Lee WJ ,Lee $\mathrm{SJ}$,et al. Detection of hepatocellular carcinoma: combined T2-weighted and dynamic gadoliniumenhanced MRI versus combined CT during arterial portography and CT hepatic arteriography. J Comput Assist Tomogr 2001;25: 777-785.

12. Ishii H, Okada S, Nose H, Okusaka T, Yoshimori $\mathrm{M}$, Takayama $\mathrm{T}$,et al. Local recurrence of hepatocellular carcinoma after percutaneous ethanol injection. Cancer 1996; 77: 1792-1796.

13. Gad-El-Mawla N, El Zawahri H, Mokhtar N, Mohamed N, Abdel Monaem D, Faisal S. Epidemiologic and Clinicopathologic Features of HCC in Egyptian Patients. ASCO Annual Meeting 2001; Abstract no: 3036.

14. El-Serag HB, Rudolph KL. Hepatocellular carcinoma: epidemiology and molecular carcinogenesis. Gastroenterology 2007; 132(7):2557-76.

15. Kurokawa Y, Matoba R, Takemasa I, Nakamori $\mathrm{S}$, Tsujie M, Nagano H, et al. Molecular features of non-B, non-C hepatocellular carcinoma: a PCRarray gene expression profiling study. Hepatol 2003; 39(6):1004-12.

16. Mohamed M. Epidemiology of HCV in Egypt 2004. The Afro-Arab Liver journal 2004; 3(2): 41 -52 . 
17. Attia M. Prevalence of hepatitis B and C in Egypt and Africa. Antivir. Ther 1998; 3 (Suppl 3): $1-9$.

18. Abdel-Wahab MF, Sultan A, El-Ebidy G. Hepatocellular carcinoma in Mansoura-Egypt: experience of 385 patients at a single center. Hepatogastroenterology 2000; 47(33):663-8.

19. Kew M. Hepatic tumors and cysts. In: Feldman M, Friedman LS, Sleisenger MH, eds. Gastrointestinal and Liver Disease. WB Saunders, Philadelphia 2002 ; 1577-1602.

20. Peng ZW, Zhang Y J, Chen MS, Lin XJ, Liang $\mathrm{HH}$, Shi C. Radiofrequency ablation as first-line treatment for small solitary hepatocellular carcinoma: Long-term results. EJSO 36 (2010) $1054 \mathrm{e} 1060$.

21. Schwartz M. Liver transplantation for hepatocellular carcinoma. Gastroenterology 2004; 127:S268-76.

22. Sung YM ,Choi D, Lim HK, Lee WJ, Kim SH, Kim MJ, et al . Long term results of percutaneous ethanol injection for treatment of hepatocellular carcinoma in Korea. Korean $J$ Radiology 2006; 7: 187-192.

23. Livarghi T, Goldberg S, Lazzaroni S. Small hepatocellular carcinoma:treatment with radiofrequency ablation versus ethanol injection. Radiology 1999; 210: 655-61.

24. Shiina S, Tagawa K, Niwa Y, Unuma T, Komatsu Y, Yoshiura K, et al. Percutaneous ethanol injection therapy for hepatocellular hepatocarcinoma: Results in 146 patients. AJR 1993; 160: 1023 - 28.

25. Farres MT, de Baere T, Lagrange C, Ramirez L, Rougier R, Munck JN, et al . Percutaneous Mitoxantrone Injection for Primary and Seconrary Liver Tumors. Cardiovascular and Interventional Radiology 1998; 21: 399-403.

26. Hoffmann W, Reichel H, Schiebe M. Intrapericardial instillation of mitoxantrone in malignant pericarditis: Histopathological appearance. Reg Cancer Treat 1993; 2: 91-99. 